\title{
Polypropylene versus Polyester Mesh for Laparoscopic Inguinal Hernia Repair: Short-Term Results of a Comparative Study ${ }^{*}$
}

\author{
Mike Ralf Langenbach ${ }^{1}$, Stefan Sauerland ${ }^{2}$ \\ ${ }^{1}$ Department of Surgery II, Helios St. Elisabeth Klinik Oberhausen, University of Witten/Herdecke, Oberhausen, Germany \\ ${ }^{2}$ Institute for Research in Operative Medicine, University of Witten/Herdecke, Cologne, Germany \\ Email: mike-ralf.langenbach@helios-kliniken.de
}

Received November 26, 2012; revised December 28, 2012; accepted January 7, 2013

\begin{abstract}
Background: Polypropylene meshes are commonly used in laparoscopic inguinal hernia repair, although they may cause complications. In this prospective study, a polyester mesh was compared to a polypropylene mesh. Methods: Transabdominal preperitoneal (TAPP) laparoscopic repair was performed in 160 consecutive male patients suffering from unilateral inguinal hernia. The first 80 cases received a polypropylene mesh (Parietene ${ }^{\circledR}$, Covidien, France), and a polyester mesh (Parietex ${ }^{\circledR}$, Covidien, France) was implanted in the second half of patients. Both groups were comparable with respect to clinical and demographic variables. Patients rated their pain using the visual analogue scale (VAS), and ultrasonography was performed on postoperative days 1 and 3 to measure seroma formation. Results: The duration of surgery and the length of stay were similar in both groups. Postoperative pain, measured on days 1 and 3 , was significantly less in patients who had received a polyester mesh as compared to the polypropylene group. The size of local seroma was also significantly reduced in the polyester group. Complication rates were $10 \%$ in the polypropylene and $9 \%$ in the polyester group and included one early recurrence in each group. Conclusions: Polyester meshes may be useful in TAPP, as this mesh material produces less foreign body reaction with less seroma formation and lower pain levels than conventional polypropylene.
\end{abstract}

Keywords: TAPP; Inguinal Hernia; Polypropylene; Polyester; Mesh; Pain

\section{Introduction}

Herniotomy is one of the most common surgical therapies [1]. The laparoscopic approaches are nowadays well-established procedures for managing an inguinal hernia repair. Worldwide over a million meshes are implanted every year. The discussion about the ideal mesh with the highest biocompatibility is still going on. Meshprostheses in humans cause inflammatory reactions. The aim of the mesh used in hernia repair should be to reinforce the abdominal wall without reducing the mobility by excessive scarring [2-10]. Complications such as pain with ejaculation, discomfortable urination, foreign body awareness and reduced life quality are described in the long-term follow-up. In different studies nearly five percent of all patients with implanted meshes because of a primary inguinal hernia suffer from chronic pain [6-11]. The majority of human randomised controlled trials in laparoscopic hernia surgery left the choice of the type of the mesh to the individual surgeon's preference and cost

*Disclosures: Drs. Mike Ralf Langenbach and Stefan Sauerland have no conflicts of interest or financial ties to disclose. considerations $[12,13]$. It has been observed that choice of the mesh-prothesis in inguinal hernia repair is far more important than technique as a determinant of outcome $[12,13]$. The extent of the foreign-body reaction with its provoked scar tissue formation seems to depend on the amount and structure of the incorporated material [14-17]. In spite of markedly reducing recurrence rates and providing a tension-free technique with reduced postoperative pain and fast recovery, the prosthetic material is often linked to several complications $[17,18]$. Permanent relief of pain or discomfort and low incidence of periand postoperative complications and recurrence rates are the goals of successful hernia repair. Mainly polypropylene meshes are used. In international studies on polyester meshes used for laparoscopic inguinal hernia repair it was described that patients showed no complications related to the mesh and identified prospective technical and long-term advantages using polyester mesh [19]. Lichtenstein et al. published the data of 1000 operations with polypropylene meshes (Marlex ${ }^{\circledR}$ ) without any recurrences 5 years after surgery. In the year 1975 Rene Stoppa used polyester meshes $\left(\right.$ Dacron $\left.^{\circledR}\right)$ placed in the 
preperitoneal space without fixing sutures. Know days we have three big groups of material concerning nonresorbable meshes: polypropylene, polyester and politetrafluoroethylene. Still in literature there is no consensus which material has the best biocompatibility in humans. Polyester is a hydrophilic material as opposed to hydrophobic material such as polypropylene or polytetrafluoroethylene and thus encourages early biologic fixation and collagen ingrowth into surrounding tissue. Polyester has also been used as an implanted material in humans for decades in the form of vascular grafts with good safety record [20].

We routinely perform transabdominal preperitoneal (TAPP) laparoscopic hernia repair. We have used two different meshes for hernia repair: Parietene ${ }^{\circledR}$ mesh (Covidien, France) that is a pure polypropylene mesh 2009 and Parietex ${ }^{\circledR}$ (Covidien, France) that consists of polyester from 2010 to 2011 on consecutive male patients undergoing laparoscopic inguinal hernia repair for primary, one-sided hernia. The aim of our study was to evaluate the effect of type of mesh used during laparoscopic inguinal hernia repair on mean-time outcomes focusing on pain, foreign body awareness, complications, development of seromas, patient satisfaction and recurrence.

\section{Materials and Methods}

\subsection{Study Design}

In 2009 laparoscopic hernia repair in our institution was performed using the pure polypropylene mesh Parietene ${ }^{\circledR}$ (Covidien, France). After obtaining institutional review board approval standardized questionnaires were used to document complications, development of postoperative seromas, development of pain and possible recurrence. Between March 2009 and June 2010 the laparoscopic hernia repair for one-sided hernia was done routinely by using the pure polyester mesh Parietex ${ }^{\circledR}$ (Covidien, France). Also these patients were documented with the same standardized questionnaires as the group before. All patients were studied prospectively with evaluation of intraoperative and postoperative results: We surveyed patients up to three days after the operation. Each eligible, consenting participant was included for final analysis. We reviewed patients' demographics, surgical time and type of surgical procedure (Table 1). The size of hernia was also documented. At the first and third postoperative day pain was documented by visual scale units and possible seroma formations were measured by ultrasound.

\subsection{Patients}

160 male patients with a one-sided, primary inguinal hernia undergoing an endoscopic hernia repair (TAPP) and fulfilling the criteria were included into the study. Inclusion criteria were: male patients, one-sided inguinal hernia, aged between 20 and 82 years, body mass index (BMI) less than $30 \mathrm{~kg} / \mathrm{m}^{2}$. Exclusion criteria were: peripheral arterial disease worse than clinical stage IIb, recurrent inguinal and scrotal hernia, neurological affections or paresthesia of the genital region or the lateral region of the proximal lower extremity, polyneuropathy, disturbance of the testicular blood circulation with testicular atrophy, therapy with anticoagulative drugs, chronic back pain, intraoperative conversion to open procedures, hydrocele, epididymitis, funiculitis, femoral hernia or incarceration.

Overall we analysed 80 patients in the group with the pure polypropylene mesh and 80 patients in the group the pure polyester mesh. In each group we found chronic obstructive pulmonary disease (COPD), diabetes mellitus, hypercholesterinemia and hyperlipidemia, arterial hypertension, and coronary heart disease in comparable frequency (Table 2).

In the group the the pure polyester mesh we found in $42 \%$ a left-sided lateral hernia inguinalis, in $44 \%$ a right-sided hernia inguinalis lateralis, and in $14 \%$ a right sided hernia inguinalis medialis. In the group with the pure polyester mesh we had 39\% patients with a rightsided hernia inguinalis lateralis and $10 \%$ with a rightsided hernia inguinalis medialis. In this group we found also left-sided hernia inguinalis lateralis in $41 \%$ and leftsided hernia inguinalis medialis in $10 \%$. The diameter of the hernia was measured before the implantation of the mesh (Table 2).

\subsection{Mesh}

We used two types of meshes for consecutive patients; from January 2009 to December 2009 we used a $15 \times 10$ cm heavyweight pure polypropylene mesh (Group A). From March 2010 up to June 2010 we used a $15 \times 10 \mathrm{~cm}$ pure polyester mesh (Group B) (Table 3).

\subsection{Endoscopic Surgical Procedure}

All patients were operated under general anesthesia. At the starting point the pneumoperitoneum was built up with $\mathrm{CO}_{2}$ at $15 \mathrm{mmHg}$. A $10 \mathrm{~mm}$ trocar was placed within the umbilicus and two $10 \mathrm{~mm}$ trocars were placed laterally. The hernia was identified and the peritoneum was dissected. We regularly separated the peritoneum far upwards into the abdominal cavity from the structures of the spermatic cord. In this way we ensured that at final closure of the peritoneum the mesh could not be raised up from its position, lying flat at the inguinal region. Special attention we gave to retrovesical dissection, so that the mesh covered the entire medical compartment without any folds, since this region is predisposed towards 
Table 1. Main results regarding duration of surgery, pain and seroma.

\begin{tabular}{cccc}
\hline & $\begin{array}{c}\text { Group 1: } \\
\text { polypropylene }\end{array}$ & $\begin{array}{c}\text { Group 2: } \\
\text { polyester }\end{array}$ & P value \\
\hline $\begin{array}{c}\text { Duration of surgery } \\
\text { in minutes }\end{array}$ & $59.5 \pm 10.1$ & $60.5 \pm 10.4$ & 0.56 \\
Pain on VAS in cm & $3.8 \pm 1.0$ & $2.5 \pm 0.8$ & $<0.001$ \\
Day 1 & $2.6 \pm 1.0$ & $1.2 \pm 0.7$ & $<0.001$ \\
Day 3 & & & \\
Seroma size in ml & $5.8 \pm 5.2$ & $3.4 \pm 1.9$ & $<0.001$ \\
Day 1 & $10.5 \pm 3.2$ & $3.7 \pm 1.9$ & $<0.001$ \\
\hline Day 3 & & & \\
\hline
\end{tabular}

Table 2. Comparability of the two groups at baseline.

\begin{tabular}{cccc}
\hline & $\begin{array}{c}\text { Group 1: } \\
\text { polypropylene }\end{array}$ & $\begin{array}{c}\text { Group 2: } \\
\text { polyester }\end{array}$ & P value \\
\hline Age in years & $55.7 \pm 10.2$ & $53.5 \pm 15.9$ & 0.29 \\
Comorbidity & $34(43 \%)$ & $32(40 \%)$ & 0.87 \\
Diabetes mellitus & $9(11 \%)$ & $8(10 \%)$ & \\
Coronary heart disease & $8(10 \%)$ & $7(9 \%)$ & \\
Obstructive lung disease & $4(5 \%)$ & $4(5 \%)$ & \\
Hypercholesteremia & $13(16 \%)$ & $11(14 \%)$ & \\
Hypertension & $11(14 \%)$ & $14(18 \%)$ & \\
Hernia diameter in cm & $6.5 \pm 1.6$ & $6.4 \pm 1.8$ & 0.67 \\
\hline
\end{tabular}

Table 3. Mesh data.

\begin{tabular}{cccc}
\hline & Unit & Parietene $^{\circledR}$ & Parietex $^{\circledR}$ \\
\hline Material & & $\begin{array}{c}100 \% \\
\text { polypropylene } \\
\text { monofilament }\end{array}$ & $\begin{array}{c}100 \% \\
\text { polyester } \\
\text { multifilament }\end{array}$ \\
$\begin{array}{c}\text { Absorbable } \\
\text { Number of pores }\end{array}$ & no $1 \mathrm{~cm}]$ & 4 & no \\
Pore size & {$[\mathrm{mm}]$} & $1.0-1.6$ & 4 \\
Thickness & {$[\mathrm{mm}]$} & 0.5 & $1.0-1.6$ \\
Weight & {$\left[\mathrm{g} / \mathrm{m}^{2}\right]$} & 78 & 38 \\
Implant size & {$[\mathrm{cm}]$} & $15 \times 10$ & $15 \times 10$ \\
\hline
\end{tabular}

recurrences. Either a polypropylene or a polyester mesh was inserted. Both meshes had the same size $(15 \times 10$ $\mathrm{cm})$. We did not cut any slits in the meshes. We tried to use a minimum number of nonresorbable tacks (Cooper's ligament, medial and lateral to the epigastric vessels; straight Endostapler, Ethicon, Norderstedt, Germany). Any application of clips between the ductus deferens and testicular vessels (the so called "triangle of doom" with underlying external iliac vessels) and lateral to the structures of the spermatic cord and below the ileopubic tract (the so called "square of doom" with the lateral femoral cutaneous nerve) was strictly avoided. In the case of medial hernias we drew the thinned-out transversalis fascia into the abdomen and fixed it with at least two clips to the ligament of Cooper, to avoid any seroma formation. The hernial sac was always completely dissected out of the hernial canal and separated from the spermatic cord structures. The peritoneum was also closed with a resorbable suture (Ethicon, Vycryl 3/0).

The two surgeons, who carried out the operative procedure, had a training status of laparoscopic hernia repair of more than five hundreds.

\subsection{Statistics}

Statistical analyses were done univariately, because baseline comparability of the two groups could be confirmed. Differences in categorical and continuous variables were tested by using Fisher's exact and Student's t test. Possible associations between continuous variables were examined by calculating Pearson's correlation coefficient. $\mathrm{P}$ values $<0.05$ were considered significant. Data are expressed as counts (with percentages) or means with standard deviations.

\section{Results}

The two groups were comparable in terms of group size, age structure, body mass index and comorbidities as well as local findings and hernia diameter (Tables 1 and 2). The overall follow-up rate was $100 \%$ after three days. There was no significant difference concerning the inhouse period of the patients: Group A 3.2 days and Group B 3.4 days. Average operation time was not significantly different (Table 1). In both groups nearly the same number of complications occurred in form of scrotal and abdominal wall hematomas, testicular contact pain at the operated side or early recurrences (Table 4) and trocar hernia. In the both groups one patient developed an early recurrence that became obvious at the first postoperative day. In both cases it was a medial hernia where the mesh was not sufficiently positioned concerning the overlapping of the border of the hernia. So, both were technical mistakes. These patients were directly reoperated and the mesh was positioned properly.

At the preoperative check four patients in Group A and 6 patients in Group B had a reduction of the Doppler signals in the testicular vessel at the hernia site. After the laparoscopic operation this reduction was negligible. In five cases the pampiniform plexus was congested at the site of the hernia. This congestion was relieved in all cases after surgery. 
Table 4. Complications.

\begin{tabular}{cccc}
\hline & $\begin{array}{c}\text { Group 1: } \\
\text { polypropylene }\end{array}$ & $\begin{array}{c}\text { Group 2: } \\
\text { polyester }\end{array}$ & P value \\
\hline Any complication & $8(10 \%)$ & $7(9 \%)$ & 1.0 \\
Hematoma & $7(9 \%)$ & $5(6 \%)$ & \\
Early recurrence & $1(1 \%)$ & $1(1 \%)$ & \\
Trocar hernia & 0 & $1(1 \%)$ & \\
\hline
\end{tabular}

Regarding pain development measured with visual scales significant $(\mathrm{P}<0.001)$ stronger pain was recorded at the first and third day after the operation in the group with the pure polypropylene mesh in comparison to the other group. Also the size of seroma formation measured by ultrasound at the first and third postoperative day was significantly $(P<0.001)$ bigger in the group where the pure polypropylene mesh was implanted in comparison to the group with the polyester mesh. Pain was significantly associated with the amount of seroma fluid on day $1(\mathrm{r}=0.22, \mathrm{P}=0.005)$ and on day $3(\mathrm{r}=0.53, \mathrm{P}<0.001)$. Patients with and without complications did not show any differences in age, hernia size or the presence of comorbidities.

The consumption of analgetics in the postoperative period (novalminsulfon drops) reflected the presence of stronger pain in Group A. The consumption of analgesic was higher in Group A than in Group B up to the third day after TAPP.

\section{Discussion}

Nowadays the introduction of biomaterials for inguinal hernia repair has become an integral component of surgery. The choice of the type of mesh in hernia surgery is often left to surgeon's preference and cost [12]. In international studies it has been mentioned that choice of the prosthesis in hernia repair is far more important than technique as a determinant of outcome [13]. It is described that polypropylene meshes, as a hydrophobic material, cause some degree of contraction and scar formation in the long-term follow-up [2]. The authors conclude that polypropylene meshes give high risk of recurrence, owing to overall decrease in the size of mesh, as well as an increased subjective foreign body feeling from contracture and scarring. Polyester seems not to suffer from these limitations because it is described as hydrophilic [2]. Our study analysis the short-term reaction of polypropylene and polyester meshes after laparoscopally being implanted because of inguinal hernia repair focussing on pain and seroma formation. The finding that we found significant more seroma formation with the patients treated with the polypropylene mesh and significant stronger pain fits in the results of other international study. In a multicenter study in the US, Ramshaw et al. described no complications related to the mesh used for total extraperitoneal laparoscopic inguinal hernia repair and identified prospective technical and long-term advantages using polyester mesh for laparoscopic inguinal hernia repair [21]. The authors describe the improved compliance as one potential advantage of polyester over polypropylene. They conclude that the improved compliance may lead potentially to less long-term shrinkage, less scaring, and subsequently, less long-term pain. Other advantages they see are the softness of polyester without loss of memory, making placement easier and its lack of tendency to stick to fat. The local tolerance and ingrowth of polyester and polypropylene types of mesh seem similar, but Nguyen et al. analysed the influence of a new monofilament polyester mesh on inflammation and matrix remodelling [22]. In this study full thickness abdominal wall defects were corrected with onlay repair suture in a rat model. In previous studies it left unclear whether mesh discrepancy in biocompatibility are due to the differences in chemical composition or filament structure $[13,21,23]$. This study compares the influence of a newly available monofilament polyester mesh to that of multifilament polypropylene, monofilament polypropylene and monofilament polytetraflouroethylene on the expression of genes important in inflammation and extracellular matrix remodelling in a rat mode. Explants were harvested seven or ninety days after repair and divided for histology and mRNA analyses using realtime quantitative polymerase chain reaction arrays to profile expression at the tissue-mesh interface. Monofilament polyester elicited a reduced foreign body reaction compared to multifilament polyester, corresponding with reduced mRNA expression of important inflammatory cytokines and matrix metalloproteinases (MMPs). Monofilament polyester also resulted in markedly reduced mRNA expression of tumour necrosis factor and MMPs 3 and 9 compared to the widely-used monofilament polypropylene mesh. The authors conclude that both chemical composition and filament structure are important mesh characteristics that may affect the wound healing response and clinical outcome.

Morrsion et al. performed laparoscopic preperitoneal inguinal hernia repair using a preformed polyester mesh without fixation. They have chosen polypropylene because of its hydrophilic properties and its early biological fixation and collagen ingrowth into surrounding tissue [20]. It is also mentioned that polyester has been used in humans for decades in the form of vascular grafts with a good safety record and thus is a good choice for placement over the delicate femoral canal structures.

In our study we found significantly bigger seroma formation in the group with the pure polypropylene than in the polyester group. This finding in the early postoperative period may be caused by stronger foreign body reaction of polypropylene. Our used meshes were both 
multifilament. So the chemical composition concerning the used material seems to bring the differences.

There are some limitations to our study that should be mentioned: First, we were not able to randomize these patients because in the initial study phase only the polypropylene mesh was available. Second, we used permanent tacks for mesh fixation, which could go along with more discomfort and pain in both mesh groups. However, these points do not negate our findings of significant more pain and bigger seroma formation in the polypropylene group.

When summarising our findings and the results of international studies it can stated that the search for the ideal mesh is still going on. As most surgeons now agree that the laparoscopic approach is a viable option for inguinal hernia repair, especially when the surgeon is experienced, the need for improved meshes is strong. The ease of using polyester as the material for mesh for laparoscopic repair may help to shorten the learning curve by making the placement easier and to reduce foreign body reaction, development of seroma formation and chronic pain.

\section{REFERENCES}

[1] J. R. Siewert, "Wandel der Eingriffshäufigkeiten in der Allgemeinchirurgie,” Der Chirurg, Vol. 64, 1990, pp. 1297-1300.

[2] B. C. Shah, M. R. Goede, R. Bayer, S. L. Buettner, S. J. Putney, C. L. McBride and D. Oleynikov, "Does Type of Mesh Used Have an Impact on Outcomes in Laparoscopic Inguinal Hernia?” American Journal of Surgery, Vol. 198, No. 6, 2009, pp. 759-764. doi:10.1016/j.amjsurg.2009.04.025

[3] M. S. Sajid, N. Ladwa, L. Kalra, K. Hutson, P. Sains and M. K. Baig, "A Meta-Analysis Examining the Use of Tacker Fixation versus No-Fixation of Mesh in Laparoscopic Inguinal Hernia Repair,” International Journal of Surgery, Vol. 10, No. 5, 2012, pp. 224-231.

[4] D. Leung and M. B. Ujiki, "Minimally Invasive Approaches to Inguinal Hernia Repair,” Journal of Long-Term Effects of Medical Implants, Vol. 20, No. 2, 2010, pp. 105-116. doi:10.1615/JLongTermEffMedImplants.v20.i2.30

[5] L. Matheron, A. Disset, F. Navarro and C. Partensky, "Prosthetic Mesh for Hernia Repair: Which Mesh for Which Indication? Analysis of the Committee for the Assessment of Devices and Health Technologies of the French National Authority for Health (HAS). Assessment of Prosthetic Meshes for Hernia Repair," Journal de Chirurgie, Vol. 146, No. 5, 2009, pp. 449-457. doi:10.1016/j.jchir.2009.09.012

[6] B. Klosterhalfen, U. Klinge, B. Hermanns and V. Schumpelick, "Pathology of Traditional Surgical Nets for Hernia Repair after Longterm Implantation in Humans," Der Chirurg, Vol. 71, No. 1, 2000, pp. 43-51. doi:10.1007/s001040051011
[7] R. Bittner, K. Kraft, C. G. Schmedt, J. Schwarz and B. Leibl, "Risks and Benefits of Laparoscopic Hernioplasty (TAPP)— 5 Years of Experience in 3400 Hernia Repairs," Der Chirurg, Vol. 69, 1998, pp. 854-858. doi:10.1007/s001040050500

[8] EU Hernia Trialists Collaboration, "Repair of Groin Hernia with Synthetic Mesh: Metaanalysis of Randomized Controlled Trials,” Annals of Surgery, Vol. 235, No. 3, 2002, pp. 322-332. doi:10.1097/00000658-200203000-00003

[9] D. Weyhe, O. Belyaev, C. Müller, K. Meurer, K. H. Bauer, G. Papapostolou and W. Uhl, "Improving Outcomes in Hernia Repair by the Use of Light Meshes-A Comparison of Different Implant Constructions Based on a Critical Appraisal of the Literature," World Journal of Surgery, Vol. 31, No. 1, 2007, pp. 234-244. doi:10.1007/s00268-006-0123-4

[10] K. Junge, U. Klinge, R. Rosch, B. Klosterhalfen and V. Schumpelick, "Functional and Morphologic Properties of a Modified Mesh for Inguinal Hernia Repair," World Journal of Surgery, Vol. 26, No. 12, 2002, pp. 1472-1480. doi:10.1007/s00268-002-6444-Z

[11] M. R. Langenbach, J. Schmidt, B. Ubrig and H. Zirngibl, "Sixty-Month Follow-Up after Endoscopic Inguinal Hernia Repair with Three Types of Mesh. A Prospective Randomized Trial,” Surgical Endoscopy, Vol. 22, No. 8, 2008, pp. 1790-1797. doi:10.1007/s00464-008-9863-6

[12] J. R. Eriksen, I. Gögenur and J. Rosenberg, "Choice of Mesh for Laparoscopic Ventral Hernia Repair,” Hernia, Vol. 11, No. 6, 2007, pp. 481-492. doi:10.1007/s10029-007-0282-8

[13] G. Champault, C. Bernard, N. Rizk and C. Polliand, "Inguinal Hernia Repair: The Choice of Prosthesis Outweights That of Technique,” Hernia, Vol. 11, No. 2, 2007, pp. 125-128. doi:10.1007/s10029-006-0179-y

[14] D. Weyhe, O. Belyaev, C. Müller, K. Meurer, K. H. Bauer, G. Papapostolou and W. Uhl, "Improving Outcomes in Hernia Repair by the Use of Light Meshes-A Comparison of Different Implant Constructions Based on a Critical Appraisal of the Literature," World Journal of Surgery, Vol. 31, No. 1, 2007, pp. 234-244. doi:10.1007/s00268-006-0123-4

[15] K. Junge, U. Klinge, R. Rosch, B. Klosterhalfen and V. Schumpelick, "Functional and Morphologic Properties of a Modified Mesh for Inguinal Hernia Repair," World Journal of Surgery, Vol. 26, No. 12, 2002, pp. 1472-1480. doi:10.1007/s00268-002-6444-z

[16] D. Weyhe, I. Schmitz, O. Belyaev, R. Grabs, K. M. Müller, W. Uhl and V. Zumtobel, "Experimental Comparison of Monofile Light and Heavy Polypropylene Meshes: Less Weight Does Not Mean Less Biological Response," World Journal of Surgery, Vol. 30, No. 8, 2006, pp. 1586-1589. doi:10.1007/s00268-005-0601-0

[17] H. Scheidbach, C. Tamme and A. Tannapfel, "In Vivo Studies Comparing the Biocompatibility of Various Polypropylene Meshes and Their Handling Properties during Endoscopic Total Extraperitoneal (TEP) Patchplasty: An Experimental Study in Pigs," Surgical Endoscopy and Other Interventional Techniques, Vol. 18, No. 2, 2004, pp. 
211-220. doi:10.1007/s00464-003-8113-1

[18] R. Horstmann, M. Hellwig, C. Classen, S. Röttgermann and D. Palmes, "Impact of Polypropylene Amount on Functional Outcome and Quality of Life after Inguinal Hernia Repair by the TAPP Procedure Using Pure, Mixed and Titanium-Coated Meshes," World Journal of Surgery, Vol. 30, No. 9, 2006, pp. 1742-1749. doi:10.1007/s00268-005-0242-3

[19] T. Schmidtbauer, R. Ladurner, K. K. Hallfeldt and T. Mussack, "Heavy-Weight versus Low-Weight Polypropylene Meshes for Open Sublay Mesh Repair of Incisional Hernia,” European Journal of Medical Research, Vol. 10, No. 6, 2005, pp. 247-253.

[20] J. E. Morrison and V. R. Jacobs, "Laparoscopic Preperitoneal Inguinal Hernia Repair Using Preformed Polyester Mesh without Fixation: Prospective Study with 1-Year Follow-Up Results in a Rural Setting," Surgical Laparoscopy Endoscopy \& Percutaneous Techniques, Vol. 18,
No. 1, 2008, pp. 33-39. doi:10.1097/SLE.0b013e318157b155

[21] B. Ramshaw, F. Abiad, G. Voeller, R. Wilson and E. Mason, "Polyester (Parietex) Mesh for Total Extraperitoneal Laparoscopic Inguinal Hernia Repair: Initial Experience in the United States,” Surgical Endoscopy, Vol. 17, No. 3, 2003, pp. 3498-3501.

[22] P. T. Nguyen, J. R. Asarias and L. M. Pierce, "Influence of a New Monofilament Polyester Mesh on Inflammation and Matrix Remodeling," Journal of Investigative Surgery, Vol. 25, No. 5, 2012, pp. 330-339.

[23] T. Poghosyan, N. Veyrie, N. Corigliano, N. Helmy, S. Servajean and J.-L. Bouillot, "Retromuscular Mesh Repair of Midline Incisional Hernia with Polyester Standard Mesh: Monocentric Expierience of 261 Consectutive Patients with a 5-Year Follow-Up," World Journal of Surgery, Vol. 36, No. 4, 2012, pp. 782-790. doi:10.1007/s00268-012-1443-1 